\title{
Green and good? \\ The investment performance of US environmental mutual funds ${ }^{*}$
}

\author{
Francisco J. Climent ${ }^{\dagger}$ Pilar Soriano ${ }^{\ddagger}$ \\ ${ }^{\dagger}$ Universitat de València \\ Avda. dels Tarongers s/n 46022 València (Spain) \\ F.Jose.Climent@uv.es \\ ${ }^{\dagger}$ Universitat de València \\ Avda. dels Tarongers s/n 46022 València (Spain) \\ Pilar.Soriano-Felipe@uv.es
}

\begin{abstract}
Increased concern for the environment has increased the number of investment opportunities in mutual funds specialized in promoting responsible environmental attitudes. This paper examines the performance and risk sensitivities of US green mutual funds vis-à-vis their conventional peers. We also analyze and compare this performance relative to other Socially Responsible Investing (SRI) mutual funds. In order to implement this analysis, we apply a CAPM-based methodology and find that in the 1987-2009 period, environmental funds had lower performance than conventional funds with similar characteristics. However, if we focus on a more recent period (20012009), green funds achieved adjusted returns not significantly different from the rest of SRI and conventional mutual funds.
\end{abstract}

JEL Classification: F30; G11; G15; G23; M14

Keywords: Socially responsible investments; Mutual funds; Performance evaluation; Ethical investing; Corporate social responsibility

\footnotetext{
${ }^{*}$ Financial support from CICYT project ECO2009-14457-C04-04, Ministerio de Ciencia e Innovación project CGL2009-09604 and Cátedra en Finanzas Internacionales - Banco Santander is gratefully acknowledged.
} 


\section{Introduction}

Socially Responsible Investment (SRI) funds are not new in the marketplace, but in recent years, we have seen an increase in interest in them, specifically with respect to funds that seek environmentally responsible investments (green funds).

According to the Social Investment Forum, about one out of every nine dollars under professional management in the United States in 2007 was involved in socially responsible investing. In particular, assets in all types of socially and environmentally screened funds (including mutual funds, exchange traded funds (ETFs), closed-end funds, other pooled products, and alternative investments) rose to \$201.8 billion in 2007. The largest share of socially and environmentally screened funds are mutual funds, with $\$ 171.7$ billion in total net assets.

SRI integrates - apart from the financial criteria - social, environmental and/or ethical criteria into the processes of analysis, selection, and choice of investment. Therefore one could classify SRI funds according to the different criteria used in their composition into a more specific group of funds: religious funds, green funds, human rights funds,... A growing concern about climate change and its risk for portfolios is intensifying the interest in SRI. In fact, climate change is now widely recognized as the most significant environmental issue facing the global economy. Therefore, investor demand is growing for portfolio opportunities in clean and green technology, alternative and renewable energy, green building and responsible property development, and other environmentally driven businesses (SIF, 2007).

However, environmental issues have received relatively limited attention in the finance literature, except as part of the more general literature on SRI.

The academic community has displayed considerable interest in the analysis of SRI investment performance. However, aggregate measures of SRI do not differentiate existing relationships between individual dimensions of SRI and returns. According to Galema et al. (2008), one of the reasons why the empirical literature yields few significant relations between SRI and expected returns may be due to the aggregation over different dimensions that have confounding effects. For example, it is possible that 
positive news on environmental friendly production is positively related to expected returns, whereas news pertaining to good employee relations is negatively related. Therefore, we will focus on a specific dimension of responsibility: environment. Undoubtedly, the contribution of each individual social investment criterion to fund return is an interesting empirical question.

In relation to SRI investment, Hamilton et al. (1993) tried to answer an important question: Could we be doing well while doing good? They presented three alternative hypothesis about the relative returns of SRI portfolios and conventional ones. The first hypothesis is that the expected returns of SRI portfolios are equal to expected returns of conventional portfolios. This is consistent with the idea that social responsibility is not priced. The second hypothesis is that the expected returns of SRI portfolios are lower than the expected returns of conventional portfolios. This would imply that the market prices the social responsibility characteristic. Finally, the third and last hypothesis is that the expected returns of SRI portfolios are higher than the expected returns of conventional portfolios. This would imply "doing well while doing good". We will also try to answer this question in relation to environmental mutual funds.

Why would we expect green fund performance to be different from other SRI or conventional funds? Firstly, increased environmental awareness on the part of investors, companies and governments suggests that one could anticipate profitable opportunities for businesses pursuing sustainable goals. This would make green funds "different" from other type of funds. Moreover, when analyzing the financial performance of green or environmental funds, one should not forget about the importance of the industry factor. Some industries (such as mining, oil and gas) may be underweighted and other (utilities) overweighted in this kind of funds, and therefore performance biased. It is likely that the constituent assets of environmental funds are highly concentrated within certain industries, and this fact should be taken into account in the analysis. Industry composition will be different in green, SRI and conventional funds. Finally, restricting the investment set may reduce the ability to reduce risk through diversification. In fact, standard portfolio choice theory would suggest that the constraint implied by environmental or SRI selection would imply lower performance. 
Environmentalists seeking to match their principles with their investment will most likely invest in environmental funds, regardless of returns. However, as Statman (2000) points out, "socially responsible investors want to do well, not merely do good". They want socially responsible mutual funds with a risk/return combination similar to that of conventional funds. Our study will investigate whether a long-run premium or penalty exists for holding environmentally responsible mutual funds. Therefore, we will focus exclusively on the environmental element of social responsibility.

Studies related to SRI could be classified into two broad branches: those that analyze it from a behavioral point of view and those that analyze its financial efficiency through different performance measures as compared to other financial alternatives. Our study would fit in this second strand of the literature. In general, these studies reach the conclusion that SRI efficiency does not differ much from that of other types of investment.

Galema et al. (2008) provide an interesting theoretical discussion on SRI and performance.

Most previous empirical studies compare the average performance of SRI and conventional funds in the US ${ }^{1}$. Nevertheless, this analysis has also been conducted in other international markets such as UK, Canada or Spain ${ }^{2}$. Earlier studies used to compare fund performance with either SRI or general indexes (see White, 1995), while more recent studies tend to evaluate fund performance with the so-called matched-pair analysis (see Mallin et al., 1995).

As stated before, comparative studies between SRI and traditional investment lead to the fact that an ethical, ecological and/or socially responsible positioning is not incompatible with profitability. In fact, there are mixed results in the literature. The vast majority of US SRI funds research finds no difference in the performance of SRI and conventional funds (see Renneboog et al. (2008) for a complete review). However, some studies find that social responsible investing might have better performance than

\footnotetext{
${ }^{1}$ See, for instance, White (1995), Statman(2000), Derwall et al. (2005), Benson et al. (2006), Gil-Bazo et al. (2010) or Derwall and Koedijk (2009).

${ }^{2}$ See, respectively, Gregory et al. (1997), Bauer et al. (2007) and Fernandez and Matallin (2008).
} 
conventional funds with similar characteristics (see Kempf and Osthoff (2007) and Galema et al. (2008) on US stock portfolios, or Fernandez and Matallin (2008) and GilBazo et al. (2010) on Spanish and US mutual funds).

There are also empirical papers analyzing those particular factors that might have an influence on performance (for instance, fund's age, size or fees). Kreander et al. (2005) find that management fee is a significant explanatory variable for the Jensen measure, while Benson et al. (2006) find no difference in fee levels nor managerial stock-picking skills between SRI and non-SRI funds. Therefore, there seems to be consensus in the fact that some factors such as age and size should be taken into account when comparing mutual fund performance. However, there is not a consensus yet on the effect of other factors. Benson et al. (2006) also point out differences in industry composition. If this factor had an effect on performance, we could see it through the analysis of a particular type of SRI funds: environmental funds. These funds will usually have a particular industry composition that will differentiate them from the rest of SRI funds. For instance, they might have a stronger weight on the natural resources or renewable energy industries.

As mentioned above, previous research on SRI mutual funds has focused on determining whether SRI funds have different financial performance than conventional funds. Diltz (1995) examined various dimensions of SRI for the US stock market. It found that employing environmental and military screens leads to a significantly positive performance, while all other screens do not have a significant impact on performance. Therefore, one might think that focusing in a subsample of the so-called SRI funds might give an insight into what is really happening with performance. In this paper, we contribute to the debate on the performance of SRI funds by identifying and separately addressing environmental funds.

There is no much academic research on green investments. Most of the existing studies focus on analyzing environmental investing from a corporate finance perspective. For instance, Heinkel et al. (2001)'s estimates indicate that more than $20 \%$ green investors are required to induce any polluting firms to reform. As far as we know, White (1995) is the only previous paper to compare environmental funds with both SRI investment and conventional investment. They find that US investors in environmental mutual funds 
earned inferior risk-adjusted returns vis-à-vis both the overall US market (proxied through the S\&P500) and a counterpart index of US socially-responsible firms (proxied through the Domini index). However, German green funds fared better, achieving riskadjusted returns not significantly different from the overall German stock market. In a similar attempt, Derwall et al. (2005) constructed and evaluated two US equity portfolios that differed in eco-efficiency. The high-ranked portfolio provided substantially higher average returns than its low-ranked counterpart over the 1995-2003 period. Therefore, there seems to be very scarce and puzzling evidence on environmental portfolios performance.

In this paper, we shed light on the debate about the financial performance of socially responsible investment mutual funds by particularly focusing on environmental funds.

It might be the case that some SRI funds owe their success/failure more to standard investment techniques (smaller firms, higher beta coefficients,...) than to a particular ethical screening technique. Therefore, we should not underestimate the importance of fund characteristics such as company size, age, managers, style, country, industry or investment universe, when comparing green versus SRI or conventional funds. All these biases can be corrected by comparing green versus SRI funds or conventional funds through a matched-pair analysis.

As far as we know, this is the first paper to analyze environmental mutual funds performance using a matched-pair analysis. The current paper extends previous research in a number of ways. First, it focuses on environmental funds rather than more general SRI funds. Second, it compares their performance with both conventional funds and SRI funds through a matched-pair analysis. Finally, we will focus on US mutual fund data for the 1987-2009 period. This includes the last decade, where socially responsible investing is thriving in the US, growing at a faster pace than the broader universe of all investment assets under professional management. Our results seem to show that investing in environmental funds might not come at the cost of reduced performance.

The remainder of the article is organized as follows. In the data section, we describe the mutual fund data set we use in our analysis. The third section discusses the empirical methodology we use in order to measure and compare mutual fund performance. 
Empirical results are presented in the fourth section and, finally, in section five we make some concluding remarks.

\section{Data}

We evaluate green fund performance relative to matched samples of SRI and conventional funds. Each green mutual fund is matched against an equally weighted portfolio of four conventional funds using fund age, end-of-period fund size, and investment objective as matching criteria. Similarly, each green mutual fund is matched against an equally weighted portfolio of two SRI funds using fund age and end-ofperiod fund size as matching criteria. We are less restrictive and use fewer funds in this case because the total population of SRI funds is smaller. In using these criteria, we control for the potentially interfering influence of, respectively, fund age, fund size, and investment scope. We select four (two) funds to compose the matched sample of conventional funds, instead of one fund, in order to mitigate the problem that mutual funds are not entirely equal in terms of the size criterion. This discrepancy averages out. The fund data are primarily from the CRSP US Mutual Fund database and cover the period 1987:03-2009:12.

\section{Mutual fund data}

Our mutual fund sample consists of US green, SRI and conventional mutual funds with open-ended equity orientation only. Hence, we exclude bond, balanced and guaranteed funds. We also exclude index funds, institutional funds and funds less than 12-months of age from our sample.

Our main source of data is the CRSP Survivor-Bias Free US Mutual Fund Database. From there, we obtain monthly information on returns and other fund characteristics. We will analyze after-fee performance, which is the normally reported performance (net of fund expenses).

In the CRSP dataset, different classes of the same fund appear as different funds. Following Statman (2000), we included only the first-established class fund. We chose 
the class fund with the most assets if two or more class funds were established simultaneously.

We obtain our list of green and SRI funds from Bloomberg ${ }^{3}$. At the end of our sample period, 10 US open-ended funds are classified as environmentally friendly funds and 27 funds are classified as Socially Responsible Investment. Only 7 out of the 10 green funds have more than one year age so that they can be included in our final sample. These funds are: Allianz RCM Global EcoTrends, DWS Climate Change, Fidelity Select Environmental Portfolio, New Alternatives, Portfolio 21, Winslow Green Growth, and Winslow Green Solutions. From the 27 SRI funds, only 19 are retail funds. SRI funds do not include those classified by Bloomberg as environmentally-friendly focused.

We will now analyze the general characteristics of the total sample of CRSP's US openended equity funds. Looking at some basic features of green, SRI and conventional mutual funds, we observe that the average green fund is typically smaller in size (133 millions of US dollars) than SRI (208) and conventional (406) funds. Expense ratios are lower in green funds (1.39) than in both SRI (1.77) and conventional (1.58) funds. Furthermore, as indicated by the number of years a fund exists, nowadays we can find green, SRI and conventional funds of similar characteristics (10.6, 12.5 and 9.75 average years respectively).

To account for the possible return differences between green mutual funds and SRI and conventional funds, we compare the performance of green funds with a matched sample of SRI and conventional funds using fund age, size and investment objective as matching criteria. For each green fund we develop a matched sample containing four (two) appropriate conventional (SRI) funds. Our final sample of actively managed, retail, US, equity mutual funds in the 1987-2009 period contains a total of 7 green funds, 14 matched SRI funds and 28 matched conventional funds. Subsequently, we compute the equal-weighted returns of all funds in our matched samples.

\footnotetext{
${ }^{3}$ We considered obtaining this list/classification from other sources such as Lipper or Morningstar. However, other classifications were too vague when defining "green funds". Bloomberg's definition was the most concrete one. All funds considered as "environmentally-friendly" by Bloomberg where included in the other lists. We preferred to use a more restrictive classification in order to be sure of the pureness of our data.
} 
Table I reports summary statistics pertaining to our matched mutual fund portfolios. Over the entire sample period, the average green fund earned a lower average annualized return than its conventional counterpart: $8.45 \%$ versus $12.67 \%$. Corresponding standard deviations (17.56\% and 15.05\%) suggest that green funds were also more risky. The average return on the green portfolio was higher for this particular sample period (8.45\%) compared to the average SRI fund return $(7.19 \%)$, but the return variability was substantially higher as well (17.56\% versus $13.79 \%)$.

\section{Factor benchmarks}

Stock market performance in the US will be measured relative to a CRSP valueweighted portfolio, the Standard and Poor's 500 Index (S\&P500), FTSE KLD 400 Social Index (KLD400), and the FTSE KLD Global Climate 100 Index (GC100). We used KLD indexes because they give us the longest time horizon so far. Moreover, KLD indexes allow us to investigate environmentally friendly performance through an exclusively green index. The KLD400 is a float-adjusted, market capitalizationweighted, common stock index of US equities launched by KLD in May 1990. The KLD400 (formerly KLD's Domini 400 Social Index) is the first benchmark index constructed using environmental, social and governance factors. It is a widely recognized benchmark for measuring the impact of social and environmental screening on investment portfolios. Similarly, the GC100 is a specialty index that promotes investment in 100 public companies that demonstrate the greatest potential for mitigating immediate and long-term causes of climate change.

As we will explain above, in order to estimate multifactor models in the spirit of Carhart (1997), we will need factor portfolios using all US stocks in the CRSP database. These factors are (1) the excess market return, (2) the return spread between a small cap portfolio and a large cap portfolio, (3) the difference in return between a value stock portfolio and a growth stock portfolio, and (4) a momentum factor. These factors are also obtained from the CRSP Survivor-Bias Free US Mutual Fund Database. 


\section{Methodology}

In order to estimate performance differences between SRI funds and a matched sample of comparable conventional funds, earlier studies compare either means of groups or use the so-called matched-pair analysis. We will use the last approach. Therefore, in order to investigate whether investors pay a price for environmentally-friendly strategies, we examine the risk and return characteristics of green mutual funds and compare them to reference groups of SRI and conventional funds.

We study the performance of green, SRI and conventional funds by using the timeseries returns of an equally weighted portfolio of funds. We evaluate the performance of the fund portfolios on a US basis from a local investor perspective: the country portfolios of mutual funds are in US dollars, evaluated against US benchmark factors while using local risk-free interest rates.

Risk-adjusted returns are the appropriate standard of comparison for evaluating investment alternatives. The academic literature has proposed different performance measures. Among them, the most successful ones have been the Treynor (1965), Sharpe (1966), and Jensen (1968) measures.

The Jensen's alpha measures a fund's outperformance through the difference between the return on the mutual fund and the return on the single-factor benchmark according to an estimated CAPM.

Formally, we would estimate the following 1-factor model:

$$
r_{t}-r_{f, t}=\alpha+\beta_{M K T}\left(r_{t}^{m}-r_{f, t}\right)+\eta_{t}
$$

where $r_{t}$ is the return on an equally weighted portfolio of funds in month $\mathrm{t}, r_{f, t}$ is the return on a local risk-free deposit, $r_{t}^{m}$ is the return of a local market proxy, $\alpha$ is the 1factor-adjusted return of the fund, $\beta_{M K T}$ measures the fund's market-risk exposure, and $\eta_{t}$ stands for the idiosyncratic return. 
However, it has been repeatedly argued that this 1-factor model is insufficiently able to explain the cross-section of expected stock returns. Therefore, most recent empirical studies use extended versions of that model. In particular, we will use the Carhart (1997) four-factor model ${ }^{4}$.

We estimate a four-factor model that includes the market, size $(S M B)$, book-to-market $(H M L)$, and momentum (MOM) factors (see Fama and French (1993) and Carhart (1997)) to control for the impact of investment styles on performance:

$$
r_{t}-r_{f, t}=\alpha+\beta_{M K T}\left(r_{t}^{m}-r_{f, t}\right)+\beta_{S M B} r_{t}^{s m b}+\beta_{H M L} r_{t}^{h m l}+\beta_{M O M} r_{t}^{m o m}+\eta_{t}
$$

where $r_{t}$ is the return on an equally weighted portfolio of funds in month $\mathrm{t}, r_{f, t}$ is the return on a local risk-free deposit, $r_{t}^{m}$ is the return of a local market proxy, $r_{t}^{s m b}, r_{t}^{h m l}$, and $r_{t}^{\text {mom }}$ are the SMB, HML and MOM factors, $\alpha$ is the four-factor-adjusted return of fund portfolios, $\beta_{M K T}, \beta_{S M B}, \beta_{H M L}$, and $\beta_{M O M}$ are the factor loadings on the four factors, and $\eta_{t}$ stands for the idiosyncratic return.

\section{Results}

Table II presents the results of applying Equation (1) on our matched samples of portfolios of green, SRI and conventional funds. The market proxy is measured by a value-weighted portfolio from the CRSP database. We compute Jensen's alpha for the three portfolios and, to enhance comparability, we also evaluate two "difference" portfolios, which are constructed by respectively subtracting SRI and conventional fund returns from green fund returns. These portfolios serve to examine differences in risk and return between the different investment approaches. Therefore, we implicitly attribute differences in the risk-adjusted average performance between green funds and $\mathrm{SRI} /$ conventional funds to environmental screens.

\footnotetext{
${ }^{4}$ Other fund performance measures can be found in Chen and Knez (1996), Ferson and Schadt (1996), Elton et al (1999), Bollen and Busse (2005), or Kosowski et al (2006).
} 
From Table II several conclusions can be drawn. First, we find no statistically significant difference in performance (alpha) between green and SRI mutual funds. The alpha estimates for the "difference" portfolio is insignificant. However, we do find statistically significant difference in performance between green and conventional mutual funds. The results indicate that green funds on average underperform conventional funds by $4.22 \%$. Second, as indicated by differences in exposure to market betas, green funds tend to be more market sensitive than both their SRI and conventional counterparts.

We ran several alternative specifications of Equation (1). For instance, in Table III we ran a specification in which we replaced the CRSP market proxy by the S\&P500 index. The alphas obtained for the three portfolios differed from the previous results. However, the alphas obtained for the "difference" portfolios differed only marginally from the previous results. This is, results still indicate that green funds on average underperform conventional funds, whereas there is no statistical difference between green and SRI performance.

Since the investment universe of green mutual fund managers is determined by environmental screens, the single-factor regression of excess green fund returns on a standard equity index may lead to biased estimates of mutual fund performance. Therefore, it is useful to consider a relevant environmental equity index to measure the performance of green mutual funds. We repeated our computations but now using the return on the FTSE KLD Global Climate 100 Index as the determinant in the singlefactor model. As the FTSE KLD Global Climate 100 Index was introduced only recently, we are only able to estimate Jensen's alpha using monthly green index returns for the period 2005-2009.

We also run a similar single-index regression using data from a broad SRI index as the market proxy. In particular, we used the KLD400 (formerly KLD's Domini 400 Social Index), from which we could obtain data for the period 1990-2009.

Results can be found in Tables IV and V, respectively. With regard to the green fund portfolio, the estimated alpha is negative and not statistically significant at the usual cutoff levels. The results therefore point out that green mutual funds are not able to 
outperform their ethical index. As expected, the adjusted R-squared from the model with the green index is higher (0.92) than the R-squared from the standard single-index model $(0.76)$ or from the model with the SRI index (0.59), indicating that the green index is more capable of explaining green mutual fund performance than both standard or SRI equity indexes. Equally remarkable are the fund betas, which reveal that the green fund portfolio is more exposed to green and standard market indexes $(\beta=1.00$ and $\beta=0.99)$ than to the SRI index $(\beta=0.89)$. These findings could be partly explained by the fact that the SRI index comprises only 400 stocks, whereas the conventional index represents a larger stock universe. Using an environmental index as the market proxy, there would be no significant difference between green funds performance and $\mathrm{SRI} /$ conventional funds performance. Using an SRI index as the market proxy, green funds underperform relative to conventional funds.

Finally, Tables VI and VII summarize the results of estimating the Carhart (1997) multi-factor model for three sample periods. If we take the full sample period (Table VI), first we notice an increase in average adjusted R-squared for the multi-factor models, compared to the 1-factor CAPM models. This confirms our expectation that multifactor models are superior in explaining mutual fund returns. Second, green funds tend to have more exposure to the market portfolio in comparison to both SRI and conventional funds, which corroborates our previous 1-factor results. Third, green funds are heavily exposed to small caps, as compared with SRI and conventional funds. Fourth, green funds do not have a significantly different exposure to the value style (HML) and momentum factor (MOM) than SRI and conventional funds. Finally, after controlling for market risk, size, book-to-market and momentum the difference in return between green and conventional funds remains statistically significant whereas it remains statistically insignificant between green and SRI funds. During the 1987-2009 period, environmental funds seemed to underperform their conventional peers.

In order to provide an insight into these results, in Table VII we divide the full sample period into two sub-periods (1987:03-2001:03 and 2001:04-2009:12). Before 2001, the green portfolio is only composed by novel green funds. After that date, more than a half of the green funds that are active at the end of the full period are already alive. Therefore, in the second sub-period, we have a more diversified and well-established green portfolio. 
In Table VII, Panel A (1987-2001), as it happened in the full period, green funds tend to have more exposure to the market portfolio in comparison to both SRI and conventional funds. Green funds are heavily exposed to small caps, as compared with SRI and conventional funds. Furthermore, green funds have a significantly different exposure to the value style (HML) than SRI funds but not different than conventional funds, whereas green funds do not have a significantly different exposure to the momentum factor (MOM) than SRI and conventional funds. Finally, after controlling for market risk, size, book-to-market and momentum, the difference in return between green and conventional/SRI funds remains statistically significant. During their initial years, environmental funds underperformed both their conventional and SRI peers.

Similarly, in Panel B (2001-2009), green funds tend to have more exposure to the market portfolio in comparison to both SRI and conventional funds, which corroborates our previous results. Also in this case, green funds are heavily exposed to small caps, as compared with SRI and conventional funds. However, green funds have a significantly different exposure to the value style (HML) than both SRI and conventional funds. As it happened in all periods considered, the momentum factor (MOM) seems not to be relevant in this model. To conclude, after controlling for market risk, size, book-tomarket and momentum, the difference in return between green and conventional or SRI funds remains statistically insignificant. In this case, in line with prior literature, environmental funds do not underperform their conventional or SRI peers.

These results, specially those related to fund performance, show that during the initial sub-period (1987-2001), the reduced number of existing/available green funds (3 out of 7) had a strong influence on the results obtained. However, once we increase the number of green funds available (2001-2009 sub-period), results corroborate what was expected from past literature. This is, green funds achieved adjusted returns not significantly different from the rest of SRI or conventional mutual funds. 


\section{Conclusions}

In this paper, we analyze the question of whether US mutual funds constrained by an environmentally-friendly investment strategy underperformed or outperformed mutual funds not subject to that constraint, during 1987-2009.

In theory, environmental and SRI funds are subject to higher risks, because they limit the number of stocks in which they invest. This is probably the reason why green funds seem to show lower returns than their conventional peers during their early years (19872001 sub-period) and, as a result of that, in the full time period considered. This would imply that the market prices the environmental responsibility characteristic. Maybe, the question should not be does being green pay, but when, who and in which sense does it pay? As other authors have suggested, an environmentally-friendly positioning will probably imply good overall management, good reputation and future value creation by stimulating innovation. Investors might be willing to pay more for green or environmentally-friendly products in the form of lower returns as compared to conventional investments.

If we focus on the whole time period considered, our results agree with White (1995). The research question "Did it pay to be a green investor?" should be answered "No, at least in the US during 1987-2009". However, these results change if we focus only on a more recent sample period (2001-2009). In this case, green funds achieved adjusted returns not significantly different from the rest of SRI or conventional mutual funds. We should probably better rely on the results obtained in this second sub-period, when we could consider equally green, SRI and conventional funds as established financial assets.

It is important to extend the analysis to different time periods as, it might be the case, green-orientated investments could fare better during market downturns. Similarly, this study should be extended to other countries. Therefore, we should be cautious interpreting results. Our results are valid for our particular sample of funds in our particular time period.

In the initial sub-period, the poor performance of environmental mutual funds could be explained by their more restricted investment set. As White (1995) points out "it may be 
improper to judge the returns on these funds using a broad-based measure such as the S\&P500". In fact, when we compared green and conventional fund performance using a green index as the market proxy, we found no statistically difference between returns.

Other explanations for the poor performance of green funds could be selection criteria, or poor fund management. It might also be the case that environmental funds have increased in value more quickly than conventional funds due to an increase in their demand. Therefore, a collapse of green stock prices would have impacted negatively on green funds performance.

But, why do we invest in green mutual funds? If we move away from the classical financial models, green investors could be irrational investors in the sense of not possessing a traditional utility function based on maximization of end-of-period wealth. Theories based on behavioral or sustainable finance would suggest that investors might possess a utility function based on a triple bottom-line: social, environmental and financial performance. In this sense, Fernandez and Matallin (2008) propose to use a Financial and Social Performance (FSP) measure. If the FPs of green funds were consistently inferior to those of the conventional funds we could then admit the existence of a financial sacrifice that could still be compensated by the social performance of the green/ethical investment.

All in all, one should take into account that past performance does not necessarily predict future performance. As results seem to show, as fund managers and investors gain experience with green-orientated investment and investment opportunities increase, we may find returns approaching those obtained on conventional funds. 


\section{Bibliography}

Bauer, R., J. Derwall and R. Otten (2007): "The Ethical Mutual Fund Performance Debate: New Evidence from Canada", Journal of Business Ethics, 70, 111-124.

Benson, K., T. Brailsford and J. Humphrey (2006): "Do Socially Responsible Fund Managers Really Invest Differently?”, Journal of Business Ethics, 65(4), 337357.

Bollen, N.P. and J.A. Busse (2005): "Short-term persistence in mutual fund performance". Review of Financial Studies, 18, 569-597.

Carhart, M. (1997): “On Persistence in Mutual Fund Performance”, The Journal of Finance, 52(1), 57-82.

Chen, Z. and P. J. Knez (1996): "Portfolio Performance Measurement: Theory and Applications", Review of Financial Studies, 9(2), 511-556.

Derwall, J. and K. Koedijk (2009): "Socially Responsible Fixed-Income Funds", Journal of Business Finance \& Accounting, 36(1) \& (2), 210-229.

Derwall, J., N. Guenster, R. Bauer and K. Koedijk (2005): "The Eco-Efficiency Premium Puzzle", Financial Analysts Journal, 61, 53-64.

Diltz, D.J. (1995): “The Private Cost of Socially Responsible Investing”, Applied Financial Economics, 5, 69-77.

Elton, E.J., M.J. Gruber and C.R. Blake (1999): "Common Factors in Active and Passive Portfolios, European Finance Review, 3(1), 53-78.

Fama, E.F. and K.R. French (1993): "Common risk factors in the returns on Bonds and stocks", Journal of Financial Economics, 33, 3-56.

Fernandez, A. and J.C. Matallin (2008): "Performance of Ethical Mutual in Spain: Sacrifice or Premium?", Journal of Business Ethics, 81, 247-260.

Ferson, W.E. and R.W. Schadt (1996): "Measuring fund strategy and performance in changing economic conditions", Journal of Finance, 51, 425-462.

Galema, R., A. Plantinga and B. Scholtens (2008): “The stocks at stake: Return and risk in socially responsible investment", Journal of Banking \& Finance, 32, 26462654.

Gil-Bazo, J., P. Ruiz-Verdú and A.P. Santos (2010): “The Performance of Socially Responsible Mutual Funds: The Role of Fees and Management Companies”, Journal of Business Ethics, 94(2), 243-263. 
Gregory, A., J. Matatko and R. Luther (1997): "Ethical Unit Trust Financial Performance: Small Company Effects and Fund Size Effects", Journal of Business Finance \& Accounting, 24(5), 705-725.

Hamilton, S., H. Jo and M. Statman (1993): "Doing Well while Doing Good? The Investment Performance of Socially Responsible Mutual Funds", Financial Analysts Journal, 49(6), 62-66.

Heinkel, R., A. Kraus and J. Zechner (2001): "The Effect of Green Investment on Corporate Behavior", Journal of Financial and Quantitative Analysis, 36(4), 431-449.

Jensen, M. (1968): “The Performance of Mutual Funds in the Period 1945-1964", Journal of Finance, 23(2), 389- 415.

Kempf, A. and P. Osthoff (2007): "The Effect of Socially Responsible Investing on Portfolio Performance”, European Financial Management, 13(5), 908-922.

Kosowski R., A. Timmermann and R. Wermers (2006): "Can mutual fund "stars" really pick stocks? New evidence from a bootstrap análisis”, Journal of Finance, 61, 2551-2595.

Kreander, N., R. Gray, D. Power and C. Sinclair (2005): "Evaluating the Performance of Ethical and Non-ethical Funds: A Matched Pair Analysis", Journal of Business Finance \& Accounting, 32(7-8), 1465-1493.

Mallin, C. A., B. Saadouni and R. J. Briston (1995): “The Financial Performance of Ethical Investment Funds", Journal of Business Finance \& Accounting, 22(4), $483-496$.

Renneboog, L., J.T. Horst and C. Zhang (2008): "Socially Responsible Investments: Institutional Aspects, Performance, and Investor Behavior", Journal of Banking and Finance, 32(9), 1723-1742.

Sharpe, W. (1966): "Mutual Fund Performance”, Journal of Business, 39(1), 119-138.

SIF (2007): 'Social Investment Forum Trends Report', Social Investment Forum.

Statman, M. (2000): "Socially Responsible Mutual Funds", Financial Analysts Journal, 56(3), 30-39.

Treynor, J.L. (1965): "How to Rate Management of Investment Funds", Harvard Business Review, 43 (1), 63-75.

White, M. A. (1995): “The Performance of Environmental Mutual Funds in the United States and Germany: Is there Economic Hope for Green Investors?", Research in Corporate Social Performance and Policy supplement ,1, 323-344. 
TABLE I

Summary statistics on green versus matched SRI and conventional funds 1987-2009

\begin{tabular}{cccc}
\hline Portfolio & Return & Standard Deviation & \# Funds \\
\hline Green & $8.45 \%$ & $17.56 \%$ & 7 \\
\hline SRI & $7.19 \%$ & $13.79 \%$ & 14 \\
\hline Conventional & $12.67 \%$ & $15.05 \%$ & 28 \\
\hline
\end{tabular}

This table reports summary statistics on green, SRI and conventional mutual funds in the sample. Green, SRI and conventional fund returns are calculated based on an equally weighted portfolio of all funds. Mean return and corresponding standard deviation are presented on an annualized basis. Sample period: 1987:03-2009:12.

\section{TABLE II}

Empirical results for 1-factor regressions

\begin{tabular}{cccc}
\hline Portfolio & $\alpha$ & $\beta$ & Adj. $\mathrm{R}^{2}$ \\
\hline Green (1) & $-3.20(-1.42)$ & $0.99(20.63)^{* * *}$ & 0.76 \\
\hline SRI (2) & $-1.53(-1.76)^{*}$ & $0.84(27.75)^{* * *}$ & 0.94 \\
\hline Conventional (3) & $1.02(0.88)$ & $0.91(25.74)^{* * *}$ & 0.92 \\
\hline
\end{tabular}

\section{Differences}

\begin{tabular}{cccc}
\hline$(1)-(2)$ & $-1.67(-0.88)$ & $0.16(4.01)^{* * *}$ & 0.07 \\
\hline$(1)-(3)$ & $-4.22(-2.42)^{* *}$ & $0.08(2.23)^{* *}$ & 0.02 \\
\hline
\end{tabular}

This table reports the results from CAPM-based regressions. To measure green, SRI and conventional mutual fund performance, we estimated the model formally defined by Equation (1), where the market proxy is a value-weighted portfolio from the CRSP database. The "difference" portfolios are constructed by subtracting either SRI or conventional mutual fund returns from the returns on the green mutual fund portfolio. T-statistics (in brackets) are derived from Newey-West heteroskedasticity and autocorrelation consistent standard errors. Sample period: 1987:03-2009:12.

*Coefficient is statistically significant at $10 \%$ level.

**Coefficient is statistically significant at $5 \%$ level.

$* * *$ Coefficient is statistically significant at $1 \%$ level. 
TABLE III

Empirical results for 1-factor regressions (S\&P500)

\begin{tabular}{cccc}
\hline Portfolio & $\alpha$ & $\beta$ & Adj. $\mathrm{R}^{2}$ \\
\hline Green (1) & $-0.74(-0.30)^{*}$ & $0.97(16.58)^{* * *}$ & 0.67 \\
\hline SRI (2) & $0.44(0.40)$ & $0.85(24.82)^{* * *}$ & 0.90 \\
\hline Conventional (3) & $3.19(2.31)^{* *}$ & $0.91(22.44)^{* * *}$ & 0.86 \\
\hline
\end{tabular}

Differences

$\begin{array}{llll}(1)-(2) & -1.17(-0.61) & 0.12(2.63)^{* * *} & 0.04\end{array}$

$\begin{array}{llll}(1)-(3) & -3.93(-2.36)^{* *} & 0.06(1.37) & 0.01\end{array}$

This table reports the results from CAPM-based regressions. To measure green, SRI and conventional mutual fund performance, we estimated the model formally defined by Equation (1), where the market proxy is the S\&P500 index. The "difference" portfolios are constructed by subtracting either SRI or conventional mutual fund returns from the returns on the green mutual fund portfolio. T-statistics (in brackets) are derived from Newey-West heteroskedasticity and autocorrelation consistent standard errors. Sample period: 1987:03-2009:12.

*Coefficient is statistically significant at $10 \%$ level.

**Coefficient is statistically significant at $5 \%$ level.

$* * *$ Coefficient is statistically significant at $1 \%$ level.

\section{TABLE IV}

Empirical results for 1-factor regressions using a green equity index

\begin{tabular}{cccc}
\hline Portfolio & $\alpha$ & $\beta$ & Adj. $\mathrm{R}^{2}$ \\
\hline Green (1) & $-3.61(-1.45)$ & $1.00(15.51)^{* * *}$ & 0.92 \\
\hline SRI (2) & $3.38(-1.22)$ & $0.74(18.56)^{* * *}$ & 0.87 \\
\hline Conventional (3) & $-2.68(-0.90)$ & $0.82(16.85)^{* * *}$ & 0.88 \\
\hline
\end{tabular}

Differences

$\begin{array}{llll}(1)-(2) & -0.22(-0.07) & 0.26(5.51)^{* * *} & 0.49 \\ (1)-(3) & -0.93(-0.35) & 0.18(5.53)^{* * *} & 0.35\end{array}$

This table reports the results from CAPM-based regressions. To measure green, SRI and conventional mutual fund performance, we estimated the model formally defined by Equation (1), where the market proxy is the FTSE KLD Global Climate 100 index. The "difference", portfolios are constructed by subtracting either SRI or conventional mutual fund returns from the returns on the green mutual fund portfolio. T-statistics (in brackets) are derived from Newey-West heteroskedasticity and autocorrelation consistent standard errors. Sample period: 2005:07-2009:12.

*Coefficient is statistically significant at $10 \%$ level.

$* *$ Coefficient is statistically significant at $5 \%$ level.

$* * *$ Coefficient is statistically significant at $1 \%$ level. 


\section{TABLE V}

Empirical results for 1-factor regressions using a SRI equity index

\begin{tabular}{|c|c|c|c|}
\hline Portfolio & $\alpha$ & $\beta$ & Adj. $\mathrm{R}^{2}$ \\
\hline Green (1) & $-3.8(-1.21)$ & $0.89(11.91)^{* * *}$ & 0.59 \\
\hline SRI (2) & $-2.10(-1.57)$ & $0.83(22.95)^{* * *}$ & 0.88 \\
\hline Conventional (3) & $0.86(0.47)$ & $0.84(16.86)^{* * *}$ & 0.81 \\
\hline \multicolumn{4}{|l|}{ Differences } \\
\hline (1)-(2) & $-1.69(-0.76)$ & $0.06(1.23)$ & 0.01 \\
\hline (1)-(3) & $-4.66(-2.31)^{* *}$ & $0.05(1.23)$ & 0.01 \\
\hline \multicolumn{4}{|c|}{$\begin{array}{l}\text { This table reports the results from CAPM-based regressions. To measure green, SRI and conventional } \\
\text { mutual fund performance, we estimated the model formally defined by Equation (1), where the market } \\
\text { proxy is the KLD400 (formerly KLD's Domini } 400 \text { Social Index). The "difference" portfolios are } \\
\text { constructed by subtracting either SRI or conventional mutual fund returns from the returns on the green } \\
\text { mutual fund portfolio. T-statistics (in brackets) are derived from Newey-West heteroskedasticity and } \\
\text { autocorrelation consistent standard errors. Sample period: 1990:05-2009:12. } \\
\text { *Coefficient is statistically significant at } 10 \% \text { level. } \\
\text { **Coefficient is statistically significant at } 5 \% \text { level. }\end{array}$} \\
\hline
\end{tabular}

TABLE VI

Multifactor regression results

\begin{tabular}{ccccccc}
\hline Portfolio & $\alpha$ & $\beta$ & SMB & HML & MOM & Adj. R $^{2}$ \\
\hline Green (1) & $-3.96(-1.99)^{* *}$ & $0.97(22.78)^{* * *}$ & $0.36(7.07)^{* * *}$ & $0.19(2.29)^{* *}$ & $-0.04(0.91)$ & 0.81 \\
\hline SRI (2) & $-1.82(-2.03)^{* *}$ & $0.85(29,11)^{* * *}$ & $0.02(1.07)$ & $0.08(2.70)^{* * *}$ & $-0.01(-0.64)$ & 0.94 \\
\hline Conventional (3) & $0.01(0.01)$ & $0.93(3.57)^{* * *}$ & $0.14(3.32)^{* * *}$ & $0.18(4.54)^{* * *}$ & $0.003(0.15)$ & 0.94 \\
\hline Differences & & & & & & \\
\hline$(1)-(2)$ & $-2.14(-1.22)$ & $0.12(2.99)^{* * *}$ & $0.33(7.38)^{* * *}$ & $0.12(1.51)$ & $-0.03(-0.71)$ & 0.25 \\
\hline$(1)-(3)$ & $-3.97(-2.34)^{* *}$ & $0.04(0.91)$ & $0.22(5.17)^{* * *}$ & $0.01(0.21)$ & $-0.05(-1.09)$ & 0.12 \\
\hline
\end{tabular}

This table reports empirical results corresponding to the multifactor regression formulated by Equation (2), where the market proxy is a value-weighted portfolio from the CRSP database, SMB denotes the difference in return between a small cap portfolio and a large cap portfolio, HML denotes the return spread between a value portfolio and a growth portfolio and MOM is the return difference between a prior 12-month winner portfolio and a prior 12-month loser portfolio. The "difference" portfolios are constructed by subtracting either SRI or conventional mutual fund returns from the returns on the green mutual fund portfolio. All parameters are annualized. T-statistics (in brackets) are derived from NeweyWest heteroskedasticity and autocorrelation consistent standard errors. Sample period: 1987:03-2009:12.

*Coefficient is statistically significant at $10 \%$ level.

$* *$ Coefficient is statistically significant at $5 \%$ level.

$* * *$ Coefficient is statistically significant at $1 \%$ level. 
TABLE VII

Multifactor regression results. Sub-period analysis.

Panel A: 1987:03-2001:03

\begin{tabular}{ccccccc}
\hline Portfolio & $\alpha$ & $\beta$ & SMB & HML & MOM & Adj. $\mathrm{R}^{2}$ \\
\hline Green (1) & $-5.88(0.002) * *$ & $0.95(0.04)^{* * *}$ & $0.39(0.06)^{* * *}$ & $0.35(0.09)^{* * *}$ & $-0.02(0.06)$ & 0.77 \\
\hline SRI (2) & $-1.53(0.001)$ & $0.79(0.04)^{* * *}$ & $-0.02(0.03)$ & $0.03(0.04)$ & $-0.003(0.02)$ & 0.92 \\
\hline Conventional (3) & $-0.44(-0.001)$ & $0.94(0.03)^{* * *}$ & $0.15(0.04)^{* * *}$ & $0.23(0.05)^{* * *}$ & $-0.02(0.03)$ & 0.94 \\
\hline Differences & & & & & & 0.27 \\
\hline$(1)-(2)$ & $-4.35(0.002)^{*}$ & $0.15(0.04)^{* * *}$ & $0.42(0.05)^{* * *}$ & $0.32(0.09)^{* * *}$ & $-0.01(0.05)$ & 0.27 \\
\hline$(1)-(3)$ & $-5.44(0.002)^{* *}$ & $0.004(0.06)$ & $0.25(0.06)^{* * *}$ & $0.12(0.08)$ & $0.002(0.05)$ & 0.09 \\
\hline
\end{tabular}

Panel B: 2001:04-2009:12

\begin{tabular}{ccccccc}
\hline Portfolio & $\alpha$ & $\beta$ & SMB & HML & MOM & Adj. R $^{2}$ \\
\hline Green (1) & $-0.96(0.002)$ & $1.17(0.09)^{* * *}$ & $0.39(0.08)^{* * *}$ & $-0.21(0.07)^{* * *}$ & $0.05(0.06)$ & 0.90 \\
\hline SRI (2) & $-2.08(0.001)$ & $0.92(0.03)$ & $0.10(0.03)$ & $0.03(0.03)$ & $0.02(0.03)$ & 0.98 \\
\hline Conventional (3) & $0.86(0.001)$ & $0.99(0.06)^{* * *}$ & $0.20(0.05)^{* * *}$ & $0.05(0.06)$ & $0.06(0.04)$ & 0.95 \\
\hline
\end{tabular}

\section{Differences}

\begin{tabular}{lllllll}
$(1)-(2)$ & $1.12(0.001)$ & $0.25(0.06)^{* * *}$ & $0.29(0.06)^{* * *}$ & $-0.24(0.06)^{* * *}$ & $0.02(0.04)$ & 0.46 \\
\hline$(1)-(3)$ & $-1.82(0.001)$ & $0.18(0.04)^{* * *}$ & $0.20(0.07)^{* * *}$ & $-0.26(0.05)^{* * *}$ & $-0.01(0.04)$ & 0.38
\end{tabular}

This table reports empirical results corresponding to the multifactor regression formulated by Equation (2), where the market proxy is a value-weighted portfolio from the CRSP database, SMB denotes the difference in return between a small cap portfolio and a large cap portfolio, HML denotes the return spread between a value portfolio and a growth portfolio and MOM is the return difference between a prior 12-month winner portfolio and a prior 12-month loser portfolio. The "difference" portfolios are constructed by subtracting either SRI or conventional mutual fund returns from the returns on the green mutual fund portfolio. All parameters are annualized. T-statistics (in brackets) are derived from NeweyWest heteroskedasticity and autocorrelation consistent standard errors.

*Coefficient is statistically significant at $10 \%$ level.

**Coefficient is statistically significant at $5 \%$ level.

$* * *$ Coefficient is statistically significant at $1 \%$ level. 